\title{
Professional development of Japanese science and physics teachers and Japanese approach in professional development: "lesson study"*
}

\author{
Dürdane BAYRAM JACOBS ${ }^{* *}$
}

\begin{abstract}
This research has been conducted to express the professional development programs for science and physics teachers in Japan. In this study especially "lesson study" was introduced. Lesson study is an approach that has been used in professional development of teachers. This approach was developed in Japan and has been used in many other countries as an effective approach in professional development of teachers. In this descriptive study, document analysis method was used. Moreover expert knowledge also used by contacting one researcher in Japan who has publications, researches and expertise in the subject of this research. By this way more accurate and up-to-date data were collected. At the end of the research, suggestions have been developed for the professional development of science and physics teachers in Turkey.
\end{abstract}

Keywords: Professional development, science and physics teachers, lesson study.

\footnotetext{
* Extracted from a PhD thesis entitled "The Comparison of Professional Development Programs for Science and Physics Teachers in Turkey, the Usa, Japan, England and Australia" prepared at Ankara University Institute of Educational Sciences with the advisor Prof. Dr. Mehmet A. Kisakürek.

** Director of Stiching voor Educatie-, Cultuur- en Migratie Onderzoek (SECMO), the Netherlands.

E-mail: durdane@secmo.nl
} 


\section{SUMMARY}

Purpose and Significance: The aim of this study is to express professional development of science and physics teachers in Japan and to express "lesson study" as one of the most effective approaches in professional development of teachers.

Method: This is a descriptive study that aims to describe the current situation. In this study, document analysis method was used. Document analysis is a method that is used often in social sciences. In document analysis it is aimed to reach the primary resources. The documents were analysed and the data were provided after analyses. In document analysis expert knowledge also can be used. In this research by contacting a Japanese researcher, expert knowledge also gathered to reach more accurate and upto-date data.

Results: The professional development programmes for science and physics teachers are organized in national, regional and school levels in Japan. Especially the programmes organized in school are important for teacher professional development. Moreover, there are also voluntary activities that are organized by teachers. Japanese government gives financial support to these voluntary activities. In Japan all teachers that are in their first year, fifth year and tenth year have to participate in professional development programmes. The universities have an important role in Japanese teachers' professional development. Universities support professional development of teachers by post-graduate education or the programs that last three or six months.

Discussion and Conclusions: "Lesson study" is one of the most effective approaches that are used in professional development of teachers. This approach has begun in Japan and disseminated to many other countries. Lesson study is defined as cooperative research in learning-teaching process. This approach is accepted as an alternative way for innovation of schools and development of teachers. In this approach a group of teachers work with courses in systematic and cooperative way and develop courses together. This is a long term study. Lesson study aims to develop a perspective into how students can learn better. Moreover this process helps teachers to develop self-reflection with co-operating other teachers. With lesson study teachers study and try different teaching approaches. Teachers join into a discussion process in which the courses that were planned and observed together discussed. 
Lesson study is composed of different steps that can last for a few months or longer:

-Planning the course with cooperating the other teachers,

- Teaching the course in a class,

- Getting the information about the observation of the course,

- Reflection, discussion and review of the course,

-Teaching the course again.

In addition to these, lesson study team prepare all the studies that they have done as a report.

Lesson study is used not only in Japan but also in many other countries as an effective way of professional development of teachers. This method should be tried in professional development of teachers in Turkey, too. This can be an effective approach for professional development of Turkish science and physics teachers. 


\title{
Japonya'da Fen ve Fizik Öğretmenlerinin Mesleki Gelişimi ve Mesleki Gelişimde Japon Yaklaşımı: "Ders Araştırması"”
}

\author{
Dürdane BAYRAM JACOBS ${ }^{* *}$
}

\begin{abstract}
ÖZ. Bu araştırmanın amacı Japonya'da fen ve fizik öğretmenlerine yönelik mesleki gelişim programlarını açıklamaktır. Bu çalışmada, özellikle "ders araştırması" yaklaşımı ele alınmaktadır. "Ders araştırması" öğretmenlerin mesleki gelişiminde kullanılan bir yaklaşımdır. "Ders araştırması" Japonya'da geliştirilmiştir ve pek çok ülkede öğretmenlerin mesleki gelişiminde başarı ile uygulanmaktadır. Tarama modelinde yapılan bu araştırmanın verilerinin toplanmasında nitel araştırma yöntemlerinden biri olan doküman incelemesi yöntemi kullanılmıştır. Araştırmada, doküman analizi yapılırken, birincil kaynaklara ulaşılmaya çalışılmış, dokümanlar çözümlenmiş, veriler analiz edilerek sunulmuştur. Doküman incelemesinde kullanılabilen yollardan biri de uzman bilgisine başvurmaktır. Bu araştırmada da Japonya'dan bir uzmanın bilgisine de başvurularak güncel ve gerçek bilgiler toplanmaya çalışılmıştır. Araştırmanın sonunda, Türkiye'de fen ve fizik öğretmenlerin mesleki gelişimi için öneriler geliştirilmiştir.
\end{abstract}

Anahtar Sözcükler: Mesleki gelişim, fen ve fizik öğretmenleri, ders araştırmasi.

\footnotetext{
* Ankara Üniversitesi Eğitim Bilimleri Enstitüsü’nde Prof. Dr. Mehmet A. Kısakürek danışmanlığında yapılmıș "Türkiye, ABD, Japonya, İngiltere ve Avustralya'da Fen ve Fizik Öğretmenlerine Yönelik Mesleki Gelişim Programlarının Karşılaştırılması” başılıklı doktora tezinin bir bölümünden yararlanılarak hazırlanmıştır.

** Yönetici- Eğitim, Kültür ve Göçmenlik Araştırmaları Vakfi (SECMO), Hollanda.

E-posta: durdane@secmo.nl
} 


\section{GíRis}

Öğretmenler eğitim sisteminin temel öğesi olarak önemli sorumluluklar taşımaktadır. Devletin eğitim politikasını uygulamaya koyan ve uygulama biçimleri ile bu politikaları etkileyenler öğretmenlerdir (Gürkan, 1987). Öğretmenler, eğitim sistemlerinin niteliksel gelişiminde anahtar faktördür. Eğitim programı reformunun başarılı ya da başarısız olmasında da anahtar rolün öğretmenlerde olduğu bilinmektedir (Banaz-Sierra, Diaz-Correa, Mellado ve Ruiz, 2008). Öğretmenler sadece kültürün aktarılmasında değil, sürekli değişen geleceğe, öğrencileri hazırlamakta anahtar rol oynamaktadır. Toplumdaki ve ailedeki değişimler ile teknolojik ve kültürel değişimler sadece eğitim programını değil aynı zamanda sınıfın ve okulun dinamiklerini de etkilemektedir (ETUCE, 1995). Öğrenci başarısı nitelikli eğitime, eğitimin verimliliği ise öğretmenlerin niteliğine bağlıdır. Bu nedenle, tüm ülkeler öğretmen yetiştirme sistemlerini geliştirmeye çalışmaktadır ("Education of Primary", 2007). Çoğu endüstrileşmiş batı ülkesinde, öğretmenler kendilerini eğitim niteliğini arttırma, daha eğitimli ve yetenekli işgücü yaratmak için öğrenci çıktılarını geliştirme konusunda baskı altında bulmaktadır (Green, Wolf ve Leney, 1999).

Öğretmen yetiştirmede temel hedef nitelikli öğretmenler yetiştirmektir. Bunun için öğretmenlerin meslek bilgisi, alan bilgisi ve genel kültür alanlarında gerekli bilgi ve becerilere sahip olması gerekmektedir (Cobb, Darling-Hammond ve Murangi, 1995). Tüm toplumlarda öğretmen yetiştirmenin her zaman önemli bir yeri olmuştur. Öğretmen yetiştirme organize olmuş, düzenli bir toplumda eğitimsel değişim gerçekleştirmek için birincil kaynak olarak görülmektedir (UNESCO, 1978). Bu nedenle çeşitli ülkelerde öğretmenlerin mesleki gelişimi göz ardı edilememekte ve öğretmenlere yönelik mesleki gelişim programlarında hem mevcut şartların hem de gelecekte oluşabilecek şartların dikkate alındığından emin olmaya çalışılmaktadır (Rodrigues, 2005). Eğitim sistemlerindeki reformların anahtar unsurlarından biri öğretmenlerin mesleki gelişimidir. Artık toplumlar eğitim sistemlerini geliştirmede öğretmenleri değiştirilmesi gereken tek değişken olarak değil ama reformlarda en anlamlı unsur olarak görmektedir (Reimers, 2003). Dünya gittikçe küreselleşirken, eğitim pek çokları tarafından ulusal kalkınma için önemli bir araç olarak görülmektedir. Ekonomik kalkınma, gelişim ve yaşam standartlarının yükselmesi eğitim ile doğrudan ilişkilidir. Stajyer öğretmenlerin eğitimi ve mevcut öğretim gücünün sürekli olarak mesleki gelişimi, eğitimsel gelişim için anahtar olarak kabul edilmektedir (Cobb, 1999).

Öğretmenlik mesleği, gittikçe karmaşıklaşan ve hızla değişen bilgi toplumunda çok sayıda beceri gerektiren bir meslektir. Günümüzde, öğretmenlerin başarılı olabilmeleri için yüksek mesleki standartlara sahip 
olmaları gerekmektedir. Bilgi çağında, bilgi toplumunu oluşturmada öğretmenlerin ve öğrencilerin sürekli gelişimi gereklidir. Öğrencilerden beklentiler arttıkça, öğretmenlerden beklentiler de artmaktadır. Daha iyi öğrenciler yetiştirebilmek için öğretmeler de sürekli olarak öğrenmeli, kendilerini geliştirmelidir (OECD, 2005). Bundan dolayı, temel öğretmen eğitimi kadar öğretmenlerin mesleki gelişimleri de önemli görülmektedir.

Mesleki gelişim genel anlamda, kişinin mesleğinde ilerlemesi olarak ifade edilmektedir. Öğretmenin mesleki gelişimi ise, öğretmenin daha fazla deneyim ve uygulama ile öğretmenliğinin gelişmesi olarak tanımlanmaktadır (Glatthorn, 1995). Mesleki gelişim, resmi deneyimleri (çalıştaylara, toplantılara veya izleme etkinliklerine katılma, vb. gibi) ve informal deneyimleri (meslekle ilgili yayınları okuma, akademik disiplinle ilgili televizyon programlarını izleme, vb. gibi) içermektedir (Ganser, 2002). Dolayısıyla mesleki gelişim kavramı, kariyer gelişimi (öğretmen profesyonel kariyer basamaklarında ilerlerken oluşan gelişme) ve personel gelişimi (bir grup öğretmenin gelişmesini sağlamak için organize edilmiş hizmetiçi eğitim programları) kavramlarından daha geniş kapsamlıdır (Reimers, 2003).

Mesleki gelişimin temel amaçlarından biri eğitim sisteminde ve sistemi oluşturan bireylerin teorik ve uygulamalı bilgi ve davranışlarında pozitif değişimi hızlandırmaktır. Değişim potansiyeli sağlamanın yanı sıra mesleki gelişim, ögretmenlere ve idarecilere bilgilerini ve niteliklerini güncelleme ve geliştirme fırsatı da sunmaktadır (Ling ve Mackenzie, 2001).

Öğretmenlerin mesleki gelişimini eğitim sistemini geliştirmek için anlamlı bir unsur olarak gören pek çok ülke, öğretmenlerin mesleki gelişimi konusunda çeşitli reformlar yapmaya çalışmaktadır. Çoğu durumda öğretmenler kişisel mesleki gelişimleri ile ilgilenseler ve çeşitli mesleki gelişim programlarına aktif olarak katılsalar da, pek çok ülkede ögretmenlerin mesleki gelişimi standartlar, nitelikler, sorumluluklar ve sonuçta verilen belge ile şekillendirilmektedir (Rodrigues, 2005).

21. yüzyılda bilgi hızla artmaktadır. Çok kısa zamanda bilgi ikiye katlanmaktadır. Dolayısıyla, bugün kendimizin ve öğrencilerimizin nasıl öğrendikleri konusunda geçmişle kıyaslanmayacak kadar daha ayrıntılı bilgi ve tecrübe bulunmaktadır (Kisakürek, 2003). Günümüzün bilgi toplumlarında, etkili öğretmenlik bilgi ve becerilerine sahip, öğrenmeyi ögrenmiş, kendini geliştirmeye ve yaşam boyu ögrenmeye açık bireyler yetiştirme gereksinimi ortaya çıkmıştır. Öğretmenler, değişen dünyanın gereksinimleri doğrultusunda bireyler yetiştirmede önemli sorumluluklara sahiptir. Bu nedenle öğretmenlerin de, gelişime, değişime ve yaşam boyu öğrenmeye açık olması gerekmektedir.

Küreselleşen dünyada, kalkınmış bir toplum olabilmek ve diğer ülkelerle rekabet edebilmek için iyi bir eğitim sistemine ve etkili öğretmenlere gereksinim vardır. Dünyada öğretmen yetiştirme alanındaki 
farklı uygulamaları ve bu alandaki eğilimleri bilmek önemli ve gereklidir. Öğretmen yetiştirme sistemimizi geliştirmek için diğer ülkelerdeki uygulamaları bilmek, karşılaşılan sorunlar ve geliştirilen çözüm yollarından haberdar olmak önemlidir.

Japonya, özellikle fen alanında dünyanın önde gelen ülkelerinden biridir. Fen ve fizik öğretmenlerinin mesleki gelişiminde farklı ülkelerdeki uygulamalardan göze çarpan bir yaklaşım Japonya'da ortaya çıkan ve pek çok ülkede kullanılan "ders araştırması" yaklaşımıdır. Bu yaklaşımın ülkemizde de daha iyi bilinmesi gereklidir.

$\mathrm{Bu}$ nedenlerden dolayı; 'Japonya'da Fen ve Fizik öğretmenlerinin mesleki gelişimi nasıl gerçekleştirilmektedir ve Japonya'da ortaya çıkan "ders araştırması" yaklaşımı nasıl uygulanmaktadır? soruları bu araştırmanın problemini oluşturmaktadır.

\section{Araştırmanın Amacı}

$\mathrm{Bu}$ araştırma, Japon fen ve fizik öğretmenlerinin mesleki gelişim programlarını incelemek, Japonya'da ortaya çıkarak dünyaya yayılan ve etkili bir mesleki gelişim yaklaşımı olarak kabul edilen "ders araştırması"nı açıklamak ve Türkiye'deki fen ve fizik öğretmenlerinin mesleki gelişimlerine ilişkin öneriler geliştirmek amacıyla yapılmıştır.

\section{Araștırmanın Önemi}

Başka ülkelerin eğitim sorunlarının çözümünde karşılaştıkları güçlükler, elde ettikleri başarılar eğitimcilere kendi sorunlarının çözümünde yararlı olmaktadır. Başka ülkelerin eğitim sistemlerine ilişkin olguların analizi, karşılaştırmalı olarak incelenmesi eğitimcilere farklı bakış açıları kazandırmaktadır (Türkoğlu, 1984).

$\mathrm{Bu}$ çalışma öğretmenlerin mesleki gelişimi hakkındadır. Günümüzde öğretmenlerin, okulların gelişimi ve öğrencilerin daha iyi öğrenmelerini sağlamak için önemli rol oynadığı tüm ülkeler ve kuruluşlar tarafından belirtilen bir gerçektir. Bu durum, Birleşmiş Milletler Eğitim, Bilim ve Kültür Organizasyonu (UNESCO) tarafindan da belirtilmektedir. UNESCO, öğretmenlerin mesleki gelişimini “önceliklerin önceliği” olarak tanımlamaktadır (UNESCO-UNEP, 1990).

$\mathrm{Bu}$ araştırma ile Japonya'da ve dünyanın pek çok ülkesinde başarı ile kullanılan "ders araştırması" yaklaşımının Türkiye'de tanıtılacağı, Türkiye'de uygulanmış, uygulanmakta olan veya uygulanabilecek fen ve fizik öğretmenlerine yönelik mesleki gelişim programları üzerinde düşünme ve tartışma yaratılacağı düşünülmektedir. Ayrıca, bu çalışma fen ve fizik 
öğretmenlerine yönelik mesleki gelişim programları ile ilgili yapılacak bilimsel çalışmalara yol gösterebilecek, fen ve fizik öğretmenlerine yönelik mesleki gelişim programlarının değerlendirilmesi ve geliştirilmesi ile ilgili fikir verebilecek ve bu konuda yapılacak uygulamalara kılavuzluk edebilecektir. Çalışmanın, Milli Eğitim Bakanlığı hizmetiçi eğitim dairesinin hizmetiçi eğitimin planlanması çalışmalarına katkıda bulunabileceği ve bu konuda yapılabilecek çalışmalara katkı sağlayabileceği de düşünülmektedir.

\section{YÖNTEM}

\section{Araștırmanın Modeli}

Araştırma, genel araştırma modelleri açısından var olan durumu, var olduğu şekilde betimlemeyi amaçlayan tarama modelidir (Karasar, 1998, s. 77). Araştırmanın verilerinin toplanmasında nitel araştırma yöntemlerinden biri olan doküman incelemesi yöntemi kullanılmıştır. Nitel araştırma, "gözlem, görüşme ve doküman analizi gibi nitel veri toplama yöntemlerinin kullanıldığı, algıların ve olayların doğal ortamda gerçekçi ve bütüncül bir biçimde ortaya konmasına yönelik nitel bir sürecin izlendiği araştırma" (Yıldırım ve Şimşek, 2005, s.39) olarak tanımlanmaktadır. Doküman incelemesi yöntemi, sosyal bilimlerde yaygın olarak kullanılan yöntemlerden biridir. Doküman incelemesi, tek başına bir yöntem olarak ya da diğer nitel yöntemlerle birlikte kullanılabilir. Bu yöntemde, araştırmada ele alınan olgu ve olaylar hakkındaki yazılı dokümanlar analiz edilir (Yıldırım ve Şimşek, 2005).

Araştırmada, doküman analizi yapılırken, birincil kaynaklara ulaşılmaya çalışılmış, dokümanlar çözümlenmiş, veriler analiz edilerek sunulmuştur. Veriler, Japonya'da öğretmenlere yönelik mesleki gelişim programları ile ilgili çeşitli basılı bilimsel kaynaklardan ve internetten yararlanılarak elde edilmiştir. Ayrıca, fen ve fizik öğretmenlerine yönelik mesleki gelişim programlarına ilişkin bilgiler bakanlık ve hükümet dokümanlarından, öğretmen örgütleri, fen veya fizik derneği gibi kuruluşların raporları, yayınları ve web sayfalarından elde edilmiştir. Doküman analizinde uzman bilgisine başvurmak da izlenen yolardan biridir (Karasar, 2005). Bu araştırmada da, Nagoya Üniversitesi (Japonya)'nden, araştırma konusu ile ilgili deneyimi ve yayınları bulunan bir öğretim üyesinin uzman bilgisine başvurulmuştur. Böylece daha güncel ve gerçek bilgiler toplanmaya çalışılmıştır. 


\section{BULGULAR}

Japonya'da ikinci dünya savaşından sonra eğitim sisteminde büyük değişiklikler olmuştur. Japonlar için eğitim geleneksel olarak önemli görülmekte ve öğretmenlere saygı duyulmaktadır. Japon öğretmenler, Japonya'nın başarılı olmasında temel unsurdur. Japon toplumu öğretmenlere önemli sorumluluklar yüklemiştir ve onlardan çok şey beklemektedir ("The Teaching Profession", 2009).

Japonya'da fen ve teknoloji eğitimine çok önem verilmektedir. Bakanlık vatandaşlar tarafından fen ve teknolojinin anlamı ve günlük yaşamla ilişkisi anlaşılabildiğinde, fen ve teknolojinin uzun süreli kullanımı ve gelişmesinin sağlanabileceğini belirtmektedir (MEXT, 2007). Fen ve teknoloji, Japon ekonomisini destekleyen bir platformdur. Düşük doğum oranı ve yaşlanan nüfus, güvenlik konuları ve çevre konuları gibi küresel problemlerle baş edebilmek için fen ve teknolojinin rolü gittikçe daha da artmıştır ("White Paper", 2008).

\section{Öğretmenlerin Mesleki Gelişimi}

Diğer ülkelerde olduğu gibi Japonya'da da öğretmenlerin hizmetiçi eğitiminin amac1, öğretmenlerin mesleki yeterliklerini geliştirmektir. Japonya'da öğretmenlerin hizmetiçi eğitimi çok boyutlu, sürekli ve sistematik bir sistemdir. Ulusal düzeyde Eğitim Bakanlığı tarafından tanımlanmış beş seviyede hizmetiçi eğitim gerçekleştirilmektedir: bölgesel eğitim kuruluşu düzeyi (yerel yönetim birimleri), belediye eğitim kuruluşu düzeyi, okul düzeyi, gönüllü eğitim kuruluşları, grupları ve öğretmenlerin bireysel eğitimi (Fujita, 2007).

Fen ve Fizik öğretmenlerinin mesleki gelişiminde, genel olarak tüm öğretmenlere yönelik olan mesleki gelişim yolları kullanılmaktadır. Bunun yanında, 1960'dan itibaren ülkenin her tarafında, hizmetiçi eğitim etkinlikleri sağlamak için bölgesel fen eğitim merkezleri kurulmaya başlanmıştır. Ayrıca, 1965 'den beri kurulmaya başlanan bölgesel eğitim merkezleri de diğer alanların yanı sıra fen bilimleri alanında etkinlikler düzenlemekte ve eğitimler organize etmektedir. 1950'lerden itibaren öğretmenler kendileri de, alanlarında gönüllü çalışma grupları oluşturmaktadır. $\mathrm{Bu}$ gönüllü etkinlikleri teşvik etmek için, hükümet 1960'dan beri bu tür etkinliklere maddi destek vermektedir ("The Consolidation", 2009).

Bakanlık, bilim ve teknolojideki yeni gelişmeler konusunda öğretmenleri eğitmek için eğitimler ve toplantılar düzenlemektedir (MEXT, 2007). Yeni atanan fen ve fizik öğretmenleri, tüm diğer yeni öğretmenler gibi stajyerlik eğitiminden geçmektedir. Bu eğitimler, bölgelere göre bazı 
küçük farklılıklar göstermektedir. Hizmetiçi eğitim programları iki kategoriye ayrılabilir. Birinci kategori, bölge eğitim kurulları tarafından yürütülen ve tüm öğretmenlerin katılması gereken programlardır. İkinci kategori, isteyen öğretmenlerin katıldığı programlardır. Birinci kategoride üç temel program vardır: yeni (ilk yılındaki) öğretmenler için programlar, beş yıllık öğretmenler için programlar ve on yıllık öğretmenler için programlar (Ogawa, 2001). Bölge eğitim kuruluşları, üniversite ve bilim merkezleri ile işbirliği halinde fen ve fizik öğretmenlerine eğitimler sunmaktadır. $\mathrm{Bu}$ eğitimler, alan gözlemleri, deneyler ve problem çözme yaklaşımını içermektedir. Ortaöğretimde çalışan tüm fen ve fizik öğretmenleri için de, mesleki kıdemlerine bağlı olarak zorunlu ve gönüllü eğitimler vardır (JSTA, 2009).

Yeni öğretmenler için programlar bir yıl sürmektedir. Her yeni fen ve fizik öğretmenin bir rehber (mentor) öğretmeni vardır. Yeni öğretmen rehberinden genellikle haftada iki gün, öğretim ve yönetim alanlarında günlük etkinliklerle ilgili bilgi ve öneriler almaktadır. Bunun yanında, tüm yeni öğretmenler haftada bir gün (30 hafta boyunca) bölge öğretmen eğitimi merkezine gitmekte, öğretim ve sınıf yönetimi konularında dersler almakta veya çalıştaylara katılmaktadır (Ogawa, 2001).

İkinci kategoride yer alan programların en önemlilerinden biri, üniversitede lisansüstü eğitim almaktır. Bu durum, "lisansüstü eğitim için okuldan ayrılma" olarak adlandırılmaktadır. Öğretmenlerin kendilerini geliştirmeleri için bir yol olarak 2001 y1lında uygulanmaya başlanmıştır. Devlet okullarında çalışan öğretmenler, lisansüstü eğitim için geçici olarak okuldan ayrılabilirler (MEXT 2001). Sınav ve görüşme ile seçilen yetenekli öğretmenler, lisansüstü programlara (Eğitim Yüksek Lisans1 programları) kayıt olurlar. İlk yıl tam zamanlı öğrenci olarak, ikinci yıl da yarı zamanlı ögrenci olarak derslere devam eder ve eğitim yüksek lisans1 (M. Ed.) derecesi ile mezun olurlar. Bu sırada, bölge eğitim kurulu maaşlarının tamamını öder. Ancak, bu programlara kayıt olan öğretmenlerin sayısı çok fazla değildir. Ibaraki bölgesinde yılda 15 öğretmen bu programlara kayıt olmaktadır (Ogawa, 2002).

Öğretmenlerin katıldığı mesleki gelişim etkinlikleri çoğunlukla teknolojinin kullanımı ve fen bilimleri öğretim teknikleri konularını içermektedir (NCES, 2006).

Üniversitelerde öğretmenlere yönelik, üç veya altı aylık mesleki gelişim programları da vardır. Bu programlara katılacak öğretmenler bölge eğitim kurulu tarafindan seçilirler. $\mathrm{Bu}$ programlara katılan öğretmenler, bulundukları çevredeki diğer fen ve fizik öğretmenlerine liderlik yaparlar. Bunun yanında, her bölgedeki öğretmen eğitimi merkezleri, öğretmenlere yönelik yaz tatilinde de açık olan programlar sunar (Ogawa, 2002). Beş ve 
on yıllık öğretmenlere yönelik olarak bölge öğretmen eğitimi merkezinde gerçekleştirilen hizmetiçi eğitimlerde; dersler, çalıştaylar, gösteriler, deneyler, sunumlar gerçekleştirirler (Ogawa, 2001).

Fen öğretmenlerinin mesleki gelişimlerini sağlamak için mevcut yollardan biri de "Matematik ve Fen Öğretmenleri için Liderlik Eğitimi" programıdır. $\mathrm{Bu}$ program ilköğretim ve ortaöğretim okullarında çalışan matematik ve fen öğretmenlerine yöneliktir. Program, gözlem, deney, bilim ve matematik alanlarında problem çözme etkinliklerini içermektedir. Amaç, alanlarında lider olabilecek öğretmenler yetiştirmektir. Program, Japon Fen ve Teknoloji Ajansı tarafindan desteklenmektedir (SPP, 2009).

Fen öğretmenlerine yönelik farklı kuruluşlar tarafından yürütülen farklı mesleki gelişim programları vardır. Bunlar, çizelge 1'de gösterilmektedir.

Çizelge 1. Fen ögretmenlerine yönelik mesleki gelişim programları

\begin{tabular}{|c|c|c|}
\hline Eyalet & Düzenleyen Kuruluș & Kurs Adı \\
\hline Hokkaido & Obihiro Üniversitesi & $\begin{array}{l}\text { Uygulama programı (ortaokul fen grubu } \\
\text { öğretmenleri için) }\end{array}$ \\
\hline Aomori & $\begin{array}{l}\text { Hirosaki Üniversitesi Eğitim } \\
\text { Fakültesi }\end{array}$ & Bilim öğretmenleri liderlik semineri \\
\hline Aomori & Hachinohe Teknoloji Enstitüsü & Enerji ve Çevre Eğitimi \\
\hline Aomori & Rokkasho, Aomori Eğitim Kurulu & İlköğretim Fen Öğretimi Atölyesi \\
\hline Miyagi & Miyagi & Yeni Bilim ve Teknoloji Desteği \\
\hline Miyagi & Miyagi & $\begin{array}{l}\text { Etkili Öğretim İçin Mikro Ölçekli Kimya } \\
\text { Deneyleri }\end{array}$ \\
\hline Tochigi & Tochigi İli Genel Eğitim Merkezi & Bilimsel Deneyler \\
\hline Gunma & $\begin{array}{l}\text { Maebashi Belediye Eğitim } \\
\text { Kurulu }\end{array}$ & $\begin{array}{l}\text { Bilim Okulu: Yeni Öğretim ve Uygulama } \\
\text { Anlayışı }\end{array}$ \\
\hline Saitama & Tachikawa-shi Saitama Müzesi & Yeni Öğretim Kılavuzlarının Kullanımı \\
\hline Tokyo & Kansai Japonya Derneği & İlköğretim Fen Deneyleri \\
\hline Tokyo & $\begin{array}{l}\text { Tokyo Tama Birliği Bilim } \\
\text { Müzesi }\end{array}$ & $\begin{array}{l}\text { Bilimi Çekici Hale Getirmek ve Lider } \\
\text { Öğretmenler Yetiştirmek }\end{array}$ \\
\hline Tokyo & $\begin{array}{l}\text { Bilişim, Teknoloji ve Bilim } \\
\text { Vakfi }\end{array}$ & $\begin{array}{l}\text { İleri deneysel teknolojiyi kullanma becerilerini } \\
\text { geliştirme }\end{array}$ \\
\hline Shiga & Nagahama Bio-Enstitüsü & $\begin{array}{l}\text { Mutlimedya, Modelleme ve Simülasyon } \\
\text { Kullanımı }\end{array}$ \\
\hline Kochi & Kochi Üniversitesi & $\begin{array}{l}\text { İlköğretim ikinci kademe öğretmenleri için } \\
\text { Astronomi }\end{array}$ \\
\hline
\end{tabular}

Kaynak: Web: http://www.spp.jst.go.jp adresinden uyarlanmıştır.

Fen eğitimini destekleme ağı, yerel kuruluşlarla işbirliği halinde düzenlediği sempozyumlar (bilgi şölenleri) ve diğer etkinliklerle fen öğretmenlerinin mesleki gelişimlerini desteklemektedir. $\mathrm{Bu}$ ağ, fen öğretmenlerine gerçek durumlara uygulanabilecek kullanışlı bilgiler sunmaktadır (“CPSE”, 2009).

Pek çok Japon öğretmen için öğrenme ve öğretme işbirliğine dayalı bir iştir ve en iyi eğitimin, akran grupları veya ağlarda (networklerde) fikirler ve deneyimler paylaşıldığı ve yansıtmalar yapıldığı zaman gerçekleştiği 
düşünülmektedir. Öğretmenler tarafindan oluşturulan eğitim teorileri genellikle diğer öğretmenlerle yapılan sık görüşmeler ve bilgi alışverişinin sonucudur. Teorik veya soyut ilkeleri öğrenmektense, öğretmenlerin planlama, gözlem, etnografı ve alan notları, uygulamada yansitma ve sinıf etkinlikleri ile ilgili işbirliğine dayalı çalışmalarla mesleki deneyimler kazandığı düşünülmektedir (Matoba ve Sarkar, 2006).

Ibaraki bölgesinde yapılan bir çalışmada, fen öğretmenleri uzmanlıklarını, meslektaşları ile günlük iletişim yoluyla arttırdıklarını ifade etmişlerdir. Mesleki gelişimlerinde hizmetiçi eğitim programlarının, informal, günlük olarak gerçekleşen, aile veya çıraklık temeline dayanan iletişimden daha etkili olmadığını belirtmişlerdir (Ogawa, 2002). Japonya'da fen başöğretmenleri, meslektaşlarla iletişim, kitaplardan, dergilerden, televizyon ve gazetelerden edinilen bilgiler gibi yollarla sağlanan mesleki gelişimin formal hizmetiçi eğitimlerle sağlanandan daha önemli görüldüğünü belirtmektedirler (Ogura ve Hatogai, 2001; Akt. Ogawa, 2002).

\section{Ders Araştırması}

Japonya'da öğretmenlerin hizmetiçi eğitimlerinde uygulanan yaklaşımlardan biri de Jugyou kenkyu; öğrenme-öğretme sürecinde işbirliğine dayalı araştırma olarak tanımlanan yaklaşımdır. Nagoya Üniversitesi araştırma grubu tarafından "sınıf etkinliklerinde işbirliğine dayalı araştırma" olarak çevrilmiştir. Ancak, Amerika Birleşik Devletleri'ndeki araştırmacılar bu yaklaşımı, "ders araştırması (lesson study)" olarak tanımlamaktadır (Arani ve Matoba, 2006).

"Ders araştırması", öğrenci merkezli öğretimi uygulamak için, eğitsel hareketin temeli olarak Japonya'da ortaya çıkmıştır. Japonya' da öğretmenlerin mesleki gelişimi için en sık kullanılan yaklaşımdır ("What is Lesson Study", 2009). "Ders araştırması", dünyada geniş etkileri olan ve diğer ülkeler tarafından da kullanılan bir yaklaşımdır. "Ders araştırması" ifadesi, Japonca Jugyokenkyu (jugyo ders, kenkyu çalışma veya araştırma anlamına gelir) sözcügünün çevirisidir. Aslında, Jugyokenkyu derslerin çalışılmasından daha fazlasını kapsamaktadır. Bu nedenle, Jugyokenkyu "ders araştırması" olarak çevrildiğinde tam anlamını verememektedir. "Ders araştırması", derslerin incelenmesi ile öğretmenlik uygulamalarının sistematik olarak sorgulanmasıdır. İncelenen bu dersler Japoncada kenkyujugyo olarak tanımlanmaktadır. Yani, Jugyokenkyu ifadesinin tam tersidir ve araştırma veya çalışma dersi anlamına gelir (Fernandez, 2002).

$\mathrm{Bu}$ yaklaşım, dünyada okul eğitiminde yenilikçilik ve öğretmen gelişmesi için alternatif bir model olarak görülmektedir (Arani ve Fukaya, 2009). Pek çok araştırmacı bu yöntemi sınıf uygulamalarını zenginleştirmek 
ve öğretmenlerin mesleki gelişimini sağlamak için kullanmıştır (Khakbaz, 2007). Amerika Birleşik Devletleri ve İngiltere'deki eğitim araştırmacıları ve eğitimciler, "ders araştırması"nı sınıf uygulamalarını incelemek ve odağı öğretimden öğrenmeye kaydırmak isteyen öğretmenler için alternatif bir yaklaşım olarak görmektedir (Lewis, 2006; Lewis ve diğerleri, 2006; Fernandez ve diğerleri, 2003; Akt. Arani ve Fukaya, 2009). Tayland ve Singapur'da araştırmacılar, "ders araştırması"nın öğretmenlerin mesleki gelişiminde yeni bir model, öğretmen niteliği ve öğrenci başarısının artmasında yararlı bir yol olabileceğini belirtmektedir (Inprasitha, 2009; Akt: Arani ve Fukaya, 2009). Hong Kong Eğitim Enstitüsü öğretmenlerin mesleki gelişiminde "ders araştırması"nı kullanmaktadır (Lee, 2008). "Ders araştırması", Çin, Vietnam, Endonezya, İran ve Kore'de öğretmenlerin mesleki gelişiminde kullanılmaktadır ve bu alana yeni bir bakış açısı getirmiştir (Arani ve Fukaya, 2009).

"Ders araştırması", bir grup öğretmenin sistematik ve işbirliğine dayalı olarak dersler üzerinde çalıştıkları ve dersleri geliştirdikleri uzun süreli bir mesleki gelişim şeklidir. Bu çalışmalar, öğrencilerin nasıl en iyi öğrendiğine daha iyi bir bakış açısı geliştirmeyi amaçlamaktadır. Ayrıca öğretmenlere, diğer meslektaşları ile işbirliği yaparak öz-yansıtma ve gelişme alışkanlıkları kazandırmada yardımcı olan bir süreçtir ("What is Lesson Study", 2009). "Ders araştırması", öğretim uygulamalarının çalışıldığı veya denendiği bir süreçtir. Öğretmenler, birlikte planlanan ve gözlenen derslerin tartışıldığı iyi tanımlanmış bir sürece dahil olur (Khakbaz,2007).

Japon okullarında çok çeşitli okul-temelli mesleki gelişim türleri vardır. Ancak, jugyou kenkyu en anlamlı ve en temel programdır. Jugyou kenkyu, "öğretimde işbirliğine dayalı araştırma" olarak değişik şekillerde geliştirilmektedir. Genel ve sistematik olarak dört aşamalı bir döngüdür: planlama-yapma-kontrol etme-eylem. Öncelikle öğretmenler işbirliğine dayalı araştırmaları için plan yapmalıdır. Sonra bu planı uygulamalı ve son olarak da öğretimlerini gözden geçirme ve geliştirme şeklinde sürecin başarısını değerlendirmeli ve yansıtma yapmalıdır. Jugyou kenkyu ile sınıf, sadece bir iş yeri değil aynı zamanda bir mesleki gelişim kaynağı olarak, öğretmenlerin kariyerlerinde anlamlı değişiklik gerçekleştirmeleri için onlara model olabilir. Bunun yanında öğretmenler, ders planları, öğrenme materyallerinin geliştirilmesi, öğrencilerle ilgilenme ve öğrencilerin değerlendirilmesini içeren, öğrenme-öğretme sürecinde ortak sorumluluk sahibidir (Matoba ve Sarkar, 2006).

"Ders araştırması" süreci, öğretim sonunda ulaşılmak istenen hedefleri belirlemekle başlar. Ardından öğretmenler, hedefe ulaşmak için gerekli stratejileri belirleyerek ders üzerinde çalışmaya başlar. Öğretmenler dersi grup olarak planlar ve detaylı bir ders planı hazırlar. Bu aşamadan sonra, 
gruptaki öğretmenlerden biri bu ders planını uygular. Diğer grup üyeleri ise bu dersi gözlemler ve ders planı üzerine notlar alırlar. Bu dersten sonra grup üyeleri bir araya gelerek gözlem sonuçlarını paylaşır ve tartışılar. Yapılan gözlemler doğrultusunda ders planı gözden geçirilir ve gerekli değişiklikler yapılır. Bundan sonra, grubun bir diğer üyesi yeni ders planını öğretmenlik yaptığı sınıfta uygular ve diğer öğretmenler bu dersi gözler. Dersten sonra öğretmenler gözlemlerini, yorumlarını ve önerilerini paylaşır. Genellikle, "ders araştırması" birkaç gün arayla gerçekleşen iki dersle birlikte 3-4 haftalık bir süreçte 10-15 saatlik grup toplantılarını içerir (Fernandez, 2002; Honigsfeld ve Cohan, 2006). Ders araştırması sırasında gözlem yapan öğretmenler, kendi öğretimleri sırasında gözleme şansı bulamadıkları durumları gözlerler: öğrenciler nasıl düşünüyor, nasıl tepkiler veriyor, birbirleriyle neler konuşuyorlar, derste sunulan kavramları öğrenmeye ne kadar istekliler (Lewis, 2000).

"Ders araştırması", birkaç ay veya daha uzun sürebilen bir dizi planlanmış aşamadan oluşur. Genelde şu etkinlikleri içerir:

- Dersi işbirliği halinde planlama

- Sinıfta dersi gerçekleştirme

- Derse ilişkin gözlem bilgilerinin elde edilmesi

- Derse ilişkin yansitma, tartışma ve gözden geçirme

- Dersi tekrar gerçekleştirme

Bunlara ek olarak, "ders araştırması" ekibi tüm süreç boyunca yaptıkları çalışmaları ve çalışmaların sonuçlarını bir rapor haline getirir ("What is Lesson Study", 2009). Bu yöntem, öğretmenlerin düzenli olarak işbirliği yapması ve dayanışmasını destekler ve özendirir (Stoel ve Thant, 2002).

Öğretmenler genellikle hükümet tarafından desteklenen mesleki gelişim kapsamında, eğitimin bir parçası olarak "ders araştırması"na katılır. Öğretmen adayları da, eğitimleri sırasında üniversitedeki rehber öğretim elemanı ve uygulama yapmak üzere gittikleri okuldaki rehber öğretmen ile birlikte "ders araştırması"na hazırlanırlar (Fernandez, 2002).

Japonya'da başlayan "ders araştırması" (lesson study) yaklaşımı, deneyimli öğretmenleri öğretmenlik uygulamalarını denemeleri ve verimliliklerini arttırmaya çağırmaktadır (Lewis, 2002; Akt. Honigsfeld ve Cohan, 2006). Japonların "ders araştırması"nın (bazen "araştırma dersi" olarak da adlandırılmaktadır) kaynağı 1990'ların başlarına uzanmaktadır (Fernandez, 2002). Literatürde oldukça kabul gören bir yaklaşımdır (Boss, 2002; Chokshi ve Fernandez, 2004; Kelly, 2002; Staples, 2005; Stewart ve Brendefur, 2005; Watanable, 2002; Akt. Honigsfeld ve Cohan, 2006). Amerika' da da çok sayıda "ders araştırması" merkezi açılmıştır (Boss, 2002; Akt. Honigsfeld ve Cohan, 2006). "Ders araştırması", Jugyou Kenkyu, okul temelli hizmetiçi öğretmen eğitiminde temel bir program olarak 
tanımlanmaktadır. $\mathrm{Bu}$ yaklaşımda öğretmenler, okulda ve sınıfta karşılaştıkları pek çok probleme yansıtma yapabilecekleri ve kendi cevaplarını oluşturabilecekleri fırsatlar bulmaktadır (Matoba ve Arani, 2005). Japon öğretmenler, mesleki gelişimi ve öğretim becerilerini geliştirmeyi yaşamboyu devam eden bir süreç olarak görmektedir. Deneyim, kendi kendine çalışma, meslektaşlarının kendi öğretimleri hakkındaki eleştirileri ve öz yansıtmanın bu sürecin önemli kısımları olduğunu bilmektedirler. Japon öğretmenler, son eğitim konuları hakkında bir kez katılacakları çalıştaylar yerine uzun süreli öz değerlendirme ve gelişmeyle ilgilenmektedir (Matoba ve Arani, 2005). Japon öğretmenlere "ders araştırması" sürecinden ne öğrendikleri sorulduğunda, çoğunluğu "öğrenciye bakış açım gelişiyor" cevabını vermektedir (Lewis, 2000).

Fernandez ve Choksi, 2002; Akt. Jalongo'ya göre, (2003) Japon ders araştırması yaklaşımında, öğretmenler:

1. Öğrencileriyle ulaşmak istedikleri hedefe ulaşırlar. Genelde bu hedefler, öğrencilerin karşılaştı̆g 1 zorlukları inceleyerek belirlenir. Gözlemler, öğrencilerle görüşmeler ve ögrencilerin eleştirileri hedeflerin kaynağıdır. Öğretmenler, "araştırma dersleri" için işbirliği yaparak çalışırlar ve ortak amaca ulaşabilmek için öğretimlerini nasıl gerçekleştirebileceklerini birlikte sorgularlar.

2. Dersi işbirliği yaparak planlar ve detaylı bir ders planı hazırlarlar. Burada öğretmenler için temel olan, uygulama deneyimlerini paylaşmak ve öğretimi planlarken onu en etkili biçimde kullanmaktır.

3. Iş̧birliği ile oluşturulan planı uygularken, meslektaşlarını gözlemler. Bir öğretmen, diğer meslektaşları planın uygulanışını izlerken ve yansıtmalarda bulunurken öğretimi gerçekleştirir. Burada gözlemin amacı, planı uygulayan öğretmenin öğretim becerisini değerlendirmek değil, grubun planını uygulamada görmek ve dersi daha da etkili yapmak için başvurulabilecek yolları analiz etmektir.

4. Örnek dersin gözlem sonuçlarını tartışmak için bir araya gelirler. Burada odak noktası, öğrencilerin ne öğreniyor göründüğü ve nelerin onları zorladığıdır.

5. Gözlemler doğrultusunda planı gözden geçirirler. $\mathrm{Bu}$, genellikle grubun bir başka üyesi tarafından öğretimin tekrar yapılması ile sonuçlanır. Önemli olan, öğrencilerin öğrenme deneyimlerini geliştirmektir. Ders, grup tarafindan belirlenmiş olan öğrenme hedefine daha etkili bir biçimde ulaşmak için yeniden düzenlenir. Genellikle, bu düzenleme süreci belli bir süre devam eder.

6. "Ders araştırması" hakkında yansitıcı bir rapor hazırlarlar. Grup, raporu okul içinde, diğer okullarla veya bölgesel ve ulusal düzeyde paylaşmaya karar verebilir. Çoğu okul düzenli olarak, çalışmalarını diğer 
okulların personelleri ile paylaşmak ve onları davet etmek için herkese açık davet yayınlar. Japonya'da bu raporlar bazen broşür, kitap ve araştırma makalesi olarak yayınlanır.

Diğer öğretmenlerin planlama sürecini gözden geçirmelerine engel olmamak için, öğretmenlerin birlikte çalışarak geliştirdikleri dersler paylaşılmaz. Planlar, öğretmenlerin araştırmasının ürünü olarak paylaşılır. Planlar belli bir öğrenci grubu için, öğretmen grubunun ortaklaşa fikir birliğine vardığı hedeflerle başlar ve gözlemler doğrultusunda gözden geçirilir. Böylece öğretmenlerin sorgulaması ile geliştirilen derslerin durağan kalması önlenmiş olur. Bu yaklaşımda, planlama süreci mesleki gelişimi hızlandırmada önemli bir araç olarak görülmektedir (Jalongo, 2003).

Her yıl sadece birkaç ders böyle yoğun bir araştırma ve geliştirme için seçilir (Jalongo, 2003). "Ders araştırması" yapılmasını gerekli kılan kurallar yoktur. "Ders araştırması", sıradan sınıflarda sıradan öğretmenlerin uygulamalarının içinde yer alır. Öğretmenler kendileri bunun önemine ve ögretimlerini geliştirmek için gerekli olduğuna inanırlar (Paddilla ve Riley, 2003).

Öğretmenlerin grup çalışması, yansıtmalar yapması ve öğretime ilişkin geribildirimler ve tartışmalarının etkisi ile öğretimde işbirliğine dayalı araştırma (jugyou kenkyu) aşağıda belirtilen şekillerde sınıf gelişimi ve öğretim niteliğinin arttırılmasında etkili olmaktadır (Matoba ve Sarkar, 2006):

- Öğretmenler iş başında öğrenirler,

- Öğretmenler kendi sınıflarında ve okullarında öğrenenlerdir ve kendilerini nasıl geliştirmeleri gerektiği konusunda karar verme sorumlulukları vardır,

- Öğretmenler uygulamada kararlar vererek değerlendirme, planlama, öğretme, gözleme, yansitma ve dönüt süreçlerinden geçerek ögrenirler.

- Öğretmenler okuldaki her öğrencinin bilgilerini gözden geçirerek, dersleri planlayarak, diğerlerinin derslerine katılarak, gözlemleyerek, günlük konuşmalarla ve öğretimi geliştirme konusunda iletişim kurarak işbirliği yaparak öğrenirler.

- Öğretmenler kendilerini gözlemleyerek, alan notları ve etnografiyi gözden geçirerek, uygulama ile ilişkilendirerek ve projelere katılarak öğrenirler,

- Öğretmenler yansitma, değerlendirme ve öğrencilerin sınıftaki iletişimini ve etkileşimini yorumlayarak öğrenirler.

Lewis ve Tsuchida (1997) “ders araştırması”nın önemli bir rolünün de 1950'lerin geleneksel fen derslerinden bugünün eleştirel düşünmeye dayalı fen öğretimi yaklaşımına geçişi sağlaması olduğunu belirtmektedir. 
Öğretmenlerin gelişmesinde yansıtma önemli görülmektedir. Yansıtma, öğretmenin "öğreten kişi olarak öğretmen" ve "öğrenen kişi olarak öğrenci" arasındaki ilişkiyi kurabilmesi için, öğrencilerin fikirlerini belirtmelerine olanak tanıması, düşüncelerdeki farklılıkları vurgulaması açılarından önemlidir. Öğretmenler sınıflarındaki öğrencilerle ilgilenir ve öğretmenlik kariyerlerinde ilerlerken kendi öğretim yollarını bulmaya çalışırlar. Bu, öğretmenlerin okul temelli mesleki gelişime katılmaya istekli olmaları için bir farkındalık oluşturmadır. Böyle bir sonuca ulaşmak için öğretmenlerin, kendilerinin hem araştırmacı hem de karar verici olduklarının farkında olmaları gerekir (Arani, 2004).

$\mathrm{Bu}$ yaklaşım (sorgulama, planlama, eyleme dönüştürme, gözlemleme, yansıtma ve tekrar planlama) öğretmenlerin birbirlerinden öğrenmelerini sağlar. Bu tür etkinlikler öğretmenlere mesleki beceri düzeylerini ve öğrencilerle ilişkilerini geliştirme firsatları sunar (Matoba ve Arani, 2005).

\section{TARTIŞMA VE SONUÇ}

Japonya'da öğretmenlerin mesleki gelişimi; ulusal, bölgesel, belediye ve okul olmak üzere farklı düzeylerde gerçekleştirilmektedir. Özellikle okulda gerçekleşen mesleki gelişim uygulamalarına önem verilmektedir. Türkiye'de de okul temelli mesleki gelişim için girişimler bulunmakla beraber, henüz yaygınlaşmamıştır.

Japonya'da öğretmenlerin mesleki gelişiminde, gönüllü çalışma grupları da göze çarpmaktadır. Hükümet de gönüllü etkinlikleri desteklemek için, bu tür etkinliklere maddi destek sağlamaktadır. Türkiye'de de bu tür gönüllü etkinlikler mevcuttur. Öğretmenlerin hazırladığı web sayfaları ve bloglar buna örnek gösterilebilir. Öğretmenler bu yolla kendi çalışmalarını meslektaşları ile paylaşmakta ve forum bölümünde de çeşitli tartışmalar gerçekleştirebilmektedir. Ancak, Türkiye'de öğretmenler bu çalışmaları kendi özel zamanlarında ve kendi imkânları ile gerçekleştirmektedir. Bu tür çalışmalar Türkiye'de de hükümet veya Milli Eğitim Bakanlığı tarafından desteklenebilir.

Japonya'da tüm yeni (ilk y1lındaki) öğretmenler, beş yıllık öğretmenler ve on yıllık öğretmenler zorunlu olarak mesleki gelişim programlarına katılmaktadır. Bilginin ve teknolojinin hızla ilerlediği çağımızda böyle bir düzenlemenin Türkiye'de de yapılması öğretmenlerin ve dolayısıyla eğitimin niteliğini arttımada etkili olacaktır. Özellikle fen ve fizik öğretmenleri için belli aralıklarla mesleki gelişim programlarına katılmak, hem alanlarındaki hem de öğretim yöntem ve tekniklerindeki gelişmeleri öğrenmek açısından gereklidir.

Japonya'da üniversitelerin öğretmenlerin mesleki gelişiminde rol oynadığı görülmektedir. Hem "lisansüstü eğitim için okuldan ayrılma" 
olarak adlandırılan programlar ile hem de üniversitelerde düzenlenen üç veya altı aylık programlar ile üniversiteler öğretmenlerin mesleki gelişimini desteklemektedir. Türkiye'de de üniversiteler ile işbirliği yapılarak öğretmenlerin hem alanlarında hem de fen bilimleri öğretim yöntem ve tekniklerinde gelişmeleri sağlanabilir. Japonya'da üniversitelerin bilgi ve deneyiminden yararlanıldığ mümkündür.

Japonya' da ortaya çıkan ve pek çok ülkede uygulanmaya başlayan "ders araştırması" mesleki gelişimde etkili bir yaklaşımdır. Bu yaklaşım Japonya'da yıllardır başarı ile uygulanmaktadır. Öğrenme-öğretme sürecinde işbirliğine dayalı araştırma olarak tanımlanan bu yaklaşım Türkiye'de de denenebilir. Ancak, bunun için öncelikle "ders araştırması" yaklaşımını iyi anlamak önemlidir. Bu yaklaşımda amaç, işbirliği halinde çalışarak etkili bir ders planı hazırlamak, bu planı uygulamada gözleyerek, gözlemler doğrultusunda geliştirmektir. Temel amaç, öğrencilerin daha etkili öğrenmesini sağlamaktır. Türkiye'de bu yaklaşımı denerken de, yaklaşımın temel amacı göz önünde bulundurulmalı, planı uygulayan öğretmen değil, plan değerlendirilmelidir.

\section{ÖNERILER}

- Türkiye'de mesleki gelişim programları tüm öğretmenlere hemen hemen aynı içeriği sunmaktadır. Oysa yerel, bölgesel ve ulusal düzeydeki beklentileri karşılamak için bakanlık yetkilileri, okul yöneticileri ve öğretmenlerin birlikte çalışarak her öğretmenin ihtiyacına uygun olarak mesleki gelişim programlarını geliştirmeleri gerekmektedir.

- Japonya'da öğretmenlerin, meslektaşları ile işbirliğine dayalı çalışmalar yapmaları ve birbirlerinin deneyimlerinden yararlanmaları önemli ve yararlı görülmektedir. Türkiye'de fen ve fizik öğretmenlerinin mesleki gelişiminde bu tür çalışmalara daha fazla yer verilmelidir.

- Alanyazında başarılı bir mesleki gelişim yaklaşımı olarak kabul edilen ve Japonya'nın yanı sıra başka ülkelerde de kullanılan "ders araştırması" yaklaşımı Türkiye'de de denenmelidir. $\mathrm{Bu}$ yaklaşım kullanılarak fen ve fizik öğretmenlerinin mesleki gelişimi sağlanabilir.

- "Ders araştırması" yaklaşımının Türkiye'de denenebilmesi için, iyi anlaşılması gerekmektedir. Bundan dolayı, bu yönteme ilişkin yeni çalışmalar yapılmalı ve alanyazın zenginleştirilmelidir. 


\section{KAYNAKLAR}

Arani, M., R., S. (2004). Teachers Learning from each Other in Japan through Jugyou Kenkyuu: an Alternative Approach to Teachers' Professional Development. Journal of Studies in International Relations, 25, 1: 191-210.

Arani, M., R., S. ve Matoba, M. (2006). Challenges in Japanese Teachers' Professional Development: A Focus on an Alternative Perspective. Comparative Education in Teacher Training, Vol. 4, Edited by N. Popov, C. Wolhuter, C., Heler, M., Kysilka, Bulgarian Comparative Education Society and Bureau for Educational Services, pp. 107-115.

Arani, S. ve Fukaya, T. (2009). Learning Beyond Boundaries: Japanese Teachers Learning to Reflect and Reflecting to Learn.

Web: http://www.chilresearch.net/resource/research/2009/arani.htm adresinden 01.10.2009 tarihinde alınmıștır.

Banaz-Sierra, C., Diaz-Correa, L., J., Mellado, V. ve Ruiz, C. (2008). The Effect of Secondary Education Teachers' Involvement in an Action-Research Program on Their Students' Alternative Ideas on Energy. Journal of Physics Teacher Education Online. Vol. 5 (1), 20 -31.

Center for Promotion of Science Education (CPSE, 2009). Japan Science and Technology Agency.

Cobb, V., L., Darling-Hammond, L., Murangi, K. (1995). Teacher Preparation and Professional Development in APEC Members: An Overview of Policy and Practice. In L. Darling-Hammond and V. L. Cobb, (Ed.), Teacher Preparation and Professional Development in APEC Members: A Comparative Study (pp. 1-16). Washington, DC: U.S. Department of Education. See ED 383683.

Cobb, V., L. (1999). An International Comparison of Teacher Education. ERIC Digest. Web: http://www.ericdigests.org/2000-3/teaches.htm adresinden 10 Temmuz 2007'de alınmıştır.

Education of Primary and Secondary School Teachers (2007).

Web: http://www.see-educoop.net/education_in/pdf/bela_knjiga-08-cro-enlt02.pdf adresinden 02.06.2007'de alınmıştır.

ETUCE - European Trade Union Committee for Education. (1995). Teacher Education in Europe. Brussels.

Web: http://www.ibe.unesco.org/Regional/SEE/SEEpdf/etucereport 1995.pdf adresinden 02.09.2008'de alınmıştır.

Fernandez, C. (2002). Learning from Japanese Approaches to Professional Development: The Case of Lesson Study. Journal of Teacher Education, 53 (5), 393-405.

Fujita, H. (2007). The Qualifications of the Teaching Force in Japan. R. M. Ingersoll, et all. (Eds.). A Comparative Study of Teacher Preparation and Qualifications in Six Nations. Philadelphia: Consortium for Policy Research in Education.Web:http://www.cpre.org/images/stories/cpre_pdfs/sixnations_final. pdf adresinden 28.07.2009 tarihinde alınmıştır. 
Ganser, T. (2002). The new teacher mentors: Four trends that are changing the look of mentoring programs for new teachers. American School Board Journal, 189 (12), 25-27.

Glatthorn, A. (1995). Teacher Development. Anderson, L. (ed.), International Encyclopaedia of Teaching and Teacher Education (second edition). London: Pergamon Pres.

Green, A., Wolf, A., ve Leney, T. (1999). Convergence and divergence in European education and training systems. London: University of London.

Gürkan, T. (1987). Ortaöğretim Kurumlarında Öğretime İlişkin Sorunlar. Eğitim Bilimleri Fakültesi Dergisi, 20 (1-2), 305-322.

Honigsfeld, A., Cohan, A. (2006). Lesson Study Meets SIOP: Linking Two Successful Professional Development Models. Paper Presented at the AERA Conference, Chicago: USA.

Jalongo, M., R. (2003). Editorial: On Behalf of Children. Early Childhood Education Journal, 31 (2).

Japan Science and Technology Agency (JSTA), (2009). Science Teacher Training. Web:http://rikai.jst.go.jp/eng adresinden 17.10.2009'da alınmıştır.

Karasar, N. (1998). Bilimsel Araştırma Yöntemi (15. Baski). Ankara: Nobel Yayın Dağıtım.

Khakbaz, A., S. (2007). Professional Development for Mathematics Teacher Through Lesson Study.

Web:http://math.unipa.it/ grim/21_project/Khakbaz312-316.pdf adresinden 10.10.2009'da alınmıştır.

Kısakürek, M., A. (2003). 'Eleştirel Çă̆rlşımlar ve Öğrenme', Öğrenmeyi Öğrenme Etkinlikleri, 17-18 Kasım 2003, Türkiye Zekâ Vakfı ve Talim Terbiye Kurulu Başkanlığı, ODTÜ Kültür ve Kongre Merkezi, Ankara.

Lee, J., F., K. (2008). A Hong Kong Case of Lesson Study-Benefits and Concerns. Teaching and Teacher Education, 24 (5), 1115-1124.

Lewis, C. ve Tsuchida, I. (1997). Planned Educational Change in Japan: The Case of Elementary Science Instruction. Journal of Educational Policy, 12 (5), 313331.

Lewis, C. (2000). Lesson Study: The Core of Japanese Professional Development. American Educational Research Association Meetings, New Orleans. April 28, 2000.

Ling, L., M. ve Mackenzie, N. (2001). The Professional Development of Teachers in Australia. European Journal of Teacher Education, 24 (2).

Matoba, M. ve Arani, M., R., S. (2005). Learning from Japanese Approach to Teachers' Professional Development: Can Jugyou Kenkyu Work in Other Countries? A Paper Presented at the 3rd International Conference on Comparative Education in Teacher Training, Organized by the Bulgarian Comparative Education Society, Sofia, Bulgaria, 18-22 April 2005.

Matoba, M. ve Arani, M., R., S. (2006). Ethnography for Teachers' Professional Development: Japanese Approach of Investigation on Classroom Activities. Comparative Education in Teacher Training, 4, 116-125. Edited by N. Popov, 
C. Wolhuter, C. Heler ve M. Kysilka, Bulgarian Comparative Education Society and Bureau for Educational Services.

MEXT (The Ministry of Education, Culture, Sports, Science and Technology) (2001). White Paper: Japanese Government Policies in Education, Culture, Sports, Science and Technology.

Web:http://www.mext.go.jp/b_menu/hakusho/html/hpac200101/index.html adresinden 08.09.2009'da alınmıştır.

MEXT (The Ministry of Education, Culture, Sports, Science and Technology) (2007). Reform of Japan's Science and Technology System. Web:http://www.mext.go.jp/english/news/2007/03/07022214/003/007.htm adresinden 09.10.2008'de alınmıştır.

NCES (National Center for Education Statistics) (2006). Teaching Science in Five Countries: Results from the TIMMS 1999 Video Study Statistical Analysis Report. US Department of Education Institute of Education Sciences.

OECD (2005). Teachers Matter: Attracting, Developing and Retaining Effective Teachers. Web:http://www.oecd.org/edu/teacherpoliciy adresinden 04.10.2009'da alınmıştır.

Ogawa, M. (2001). Reform Japanese Style: Voyage into an Unknown and Chaotic Future. Science Education, 85 (5), 483 - 614.

Ogawa, M. (2002). How are the Novice Getting to be the Expert? : A Preliminary Case Study on Japanese Science Teachers. Journal of the Korean Association for Research in Science Education, 22 (5), (Special Issue), 1082-1102.

Paddilla, M. ve Riley, J. (2003). Guiding the New Teacher: Induction of the First Year Teachers in Japan. In E. Britton, L. Paine, D. Pimm and S. Raizen (Eds.), Comprehensive Teacher Induction: Systems for Early Career Learning ( $\mathrm{p}$. 261-295). Boston, MA: Kluwer.

Reimers, V., E. (2003). Teacher Professional Development: an International Review of the Literature. UNESCO, Paris.

Rodrigues, S. (ed.). (2005). International Perspectives on Teacher Professional Development: Changes Influenced by Politics, Pedagogy and Innovation. New York: Nova Science Publishers, Inc.

SPP: Science Partnership Project (2009). Science Camp. Web: http://spp.jst.go.jp/ adresinden 11.11.2009'da alınmıştır.

Stoel, C.,F. and Thant,T.,S. (2002). Teachers' Professional Lives- A View from Nine Industrialized Countries. Washington: Milken Family Foundation.

The Consolidation of the New Education System (2009). Teacher Training, InService Training for Web:http://www.mext.go.jp/b_menu/hakusho/html/hpbz198103/hpbz198103_ 2_202.html adresinden 02.10.2009'da alınmıştır.

The Teaching Profession. Web:http://members.tripod.com/h_javora/jed4.htm adresinden 10.05.2009 tarihinde alınmıştır.

Türkoğlu, A. (1984). Türkiye ve Fransa'da Lise Programlarının Karşılaştırmalı Olarak Incelenmesi. Ankara: Ankara Üniversitesi Eğitim Bilimleri Fakültesi Yayınları. No: 131 
UNESCO (1978). The Final Report: International Conference on Environmental Education. Paris: UNESCO.

UNESCO-UNEP (1990). Environmentally Educated Teachers: The Priority of Priorities? Conncet, 15(1), 1-3.

What is Lesson Study (2009). Web:http://www.misd.net/lessonstudy/lessonstudy.htm adresinden 01.10.2009 tarihinde alınmıştır.

White Paper on Science and Technology (2008)

Web:http://www.mext.go.jp/component/english/icsFiles/afieldfile/2009/04/23/ 1260307_2.pdf adresinden 10.10.2009'da alınmıştır.

Yıldırım, A. Şimşek, H. (2005). Sosyal Bilimlerde Nitel Araştırma Yöntemleri. 5. Baskı. Ankara: Seçkin Yayınları. 